\title{
Discrete Model of Commensalism Between Two Species
}

\author{
B. Hari Prasad \\ Department of Mathematics, Chaitanya Degree College, Hanamkonda, A.P. India. \\ sumathi_prasad73@yahoo.com \\ N. Ch. Pattabhi Ramacharyulu \\ Professor (Retd.) of Mathematics, NIT. Warangal, India.
}

\begin{abstract}
This paper deals with an investigation on discrete model of host commensal pair. The model comprises of a commensal $\left(\mathrm{S}_{1}\right)$, a host $\left(\mathrm{S}_{2}\right)$ that benefit $\mathrm{S}_{1}$, without getting effected either positively or adversely. The model is characterized by a couple of first order non-linear ordinary differential equations. In all, four equilibrium points of the model would exist and their stability criteria is discussed. The model would be stable if each of the eigen values is numerically less than one. Further the growth rates of the species are numerically estimated using Runge-Kutta fourth order scheme.
\end{abstract}

Index Terms - Characteristic matrix, Commensal, Stable, Equilibrium point, Host

AMS Classification: 92D25, 92D40

\section{INTRODUCTION}

Mathematical modeling is an important interdisciplinary activity which involves the study of some aspects of diverse disciplines. Biology, Epidemiology, Physiology, Ecology, Immunology, Bio economics, Genetics some of those disciplines. This mathematical modeling has raised to the zenith in recent years and spread to all branches of life and drew the attention of every one.

Mathematical modeling of ecosystem was initiated by Lotka[1] and by Volterra[2]. Since then, several mathematicians and ecologists May[3], Kushing[4], Smith[5], Kapur[6], contributed to the growth of this area of knowledge.

Competitive eco-systems of two species and three species with limited and unlimited resources were investigated by Srinivas[7] while Laxminarayan and Pattabhi Ramacharyulu[8] studied Prey-Predator ecological models with partial cover for the prey and alternate food for the predator. Archana Reddy[9] and Bhaskara Rama Sharma[10]investigated diverse problems related to two species competitive systems with time delay. Further Phani Kumar[11] studied some mathematical models of ecological commensalism. More recently the criteria for a four species syn eco-system was discussed at length by the present authors[12-20].

The present investigation is a study of discrete model of commensalism between two species. Figure 1 shows the schematic sketch of the system under investigation.

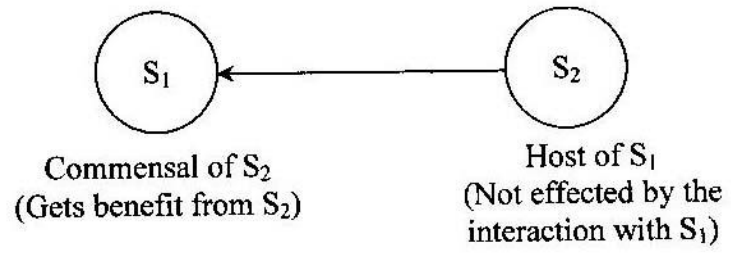

Figure 1: Schematic sketch of the system

Commensalism is a symbiotic interaction between two populations where one population $\left(S_{1}\right)$ gets benefit from $\left(S_{2}\right)$ while the other $\left(S_{2}\right)$ is neither harmed nor benefited due to the interaction with $\left(S_{1}\right)$. The benefited species $\left(\mathrm{S}_{1}\right)$ is called the commensal and the other $\left(\mathrm{S}_{2}\right)$ is called the host. Some real-life examples of commensalism are presented below.



Figure 2. Example for commensalism

1. Epiphytes are small green plants found growing on other plants for space only. They absorb water and minerals from the atmosphere by their hygroscopic roots and prepare their own food. The plants are not harmed in any way. This is shown in Figure 2. 
2. A squirrel in an oak tree gets a place to live and food for its survival, while the tree remains neither benefited nor harmed.

3. The clownfish shelters among the tentacles of the sea anemone, while the sea anemone is not effected

\section{BASIC EQUATIONS}

The model equations for two species host-commensal is given by the following system of first order non-linear differential equations employing the following notation.

\section{Notation Adopted:}

$\mathrm{N}_{1}(\mathrm{t})$ : The population strength of commensal species $\left(\mathrm{S}_{1}\right)$

$\mathrm{N}_{2}(\mathrm{t})$ : The population strength of host species $\left(\mathrm{S}_{2}\right)$

$\mathrm{t} \quad$ : Time instant

$a_{i} \quad$ : Natural growth rates of $S_{i}, i=1,2$

$a_{\text {ii }} \quad$ : Self inhibition coefficient of $S_{i}, i=1,2$

$a_{12} \quad$ : Commensal coefficient of $S_{1}$ due to $S_{2}$

$\mathrm{K}_{\mathrm{i}}=\frac{\mathrm{a}_{\mathrm{i}}}{\mathrm{a}_{\mathrm{ii}}}$ : Carrying capacities of $\mathrm{S}_{\mathrm{i}}, \mathrm{i}=1,2$

Further the variables $\mathrm{N}_{1}, \mathrm{~N}_{2}$ are non-negative and the model parameters $a_{1}, a_{2}, a_{11}, a_{12}, a_{22}$ are assumed to be non-negative constants.

The basic model equations for the growth rates of $S_{1}, S_{2}$ are

$\frac{d N_{1}}{d t}=a_{1} N_{1}-a_{11} N_{1}^{2}+a_{12} N_{1} N_{2}$

$\frac{d N_{2}}{d t}=a_{2} N_{2}-a_{22} N_{2}^{2}$

The discrete form of the equations (1) and (2) is

$$
\begin{aligned}
& N_{1}(t)=\alpha_{1} N_{1}(t-1)-a_{11} N_{1}^{2}(t-1)+a_{12} N_{1}(t-1) N_{2}(t-1) \\
& N_{2}(t)=\alpha_{2} N_{2}(t-1)-a_{22} N_{2}^{2}(t-1)
\end{aligned}
$$

where $\alpha_{1}=a_{1}+1$ and $\alpha_{2}=a_{2}+1$

\section{EQUILIBRIUM STATES}

The system under investigation has four equilibrium points defined as

$$
\mathrm{N}_{\mathrm{i}}(\mathrm{t}+1)=\mathrm{N}_{\mathrm{i}}(\mathrm{t}), \mathrm{i}=1,2
$$

i) Fully washed out state.

$$
\mathrm{E}_{0}: \overline{\mathrm{N}}_{1}=0, \overline{\mathrm{N}}_{2}=0
$$

ii) The state in which only the host $\left(S_{2}\right)$ survives and the commensal $\left(S_{1}\right)$ is washed out.

$$
\mathrm{E}_{1}: \overline{\mathrm{N}}_{1}=0, \overline{\mathrm{N}}_{2}=\mathrm{K}_{2}
$$

iii) The state in which the commensal $\left(S_{1}\right)$ only survives and the host $\left(S_{2}\right)$ is washed out.

$$
\mathrm{E}_{2}: \overline{\mathrm{N}}_{1}=\mathrm{K}_{1}, \overline{\mathrm{N}}_{2}=0
$$

iv) The Co-existent state (or) Normal steady state.

$$
\mathrm{E}_{3}: \overline{\mathrm{N}}_{1}=\mathrm{K}_{1}+\frac{\mathrm{a}_{12} \mathrm{~K}_{2}}{\mathrm{a}_{11}}, \overline{\mathrm{N}}_{2}=\mathrm{K}_{2}
$$

\section{STABILITY OF THE EQUILIBRIUM STATES}

The basic equations can be linearized about the equilibrium point $\mathrm{E}\left(\overline{\mathrm{N}}_{1}, \overline{\mathrm{N}}_{2}\right)$.We get the characteristic matrix is given by

$$
\mathrm{A}=\left[\begin{array}{cc}
\alpha_{1}-2 \mathrm{a}_{11} \overline{\mathrm{N}}_{1}+\mathrm{a}_{12} \overline{\mathrm{N}}_{2} & \mathrm{a}_{12} \overline{\mathrm{N}}_{1} \\
0 & \alpha_{2}-2 \mathrm{a}_{22} \overline{\mathrm{N}}_{2}
\end{array}\right]
$$

The equilibrium point $\mathrm{E}\left(\overline{\mathrm{N}}_{1}, \overline{\mathrm{N}}_{2}\right)$ is stable, if the absolute values of all eigen values of the matrix $A$ are less than one.

\section{4.a. Stability of equilibrium point $E_{0}$}

The characteristic matrix of this state is

$$
A=\left[\begin{array}{cc}
a_{1}+1 & 0 \\
0 & a_{2}+1
\end{array}\right]
$$

The eigen values of which are $a_{1}+1, a_{2}+1$ and the absolute values of these both are greater than one.

$$
\text { Hence, } \mathrm{E}_{0}(0,0) \text { is unstable. }
$$

\section{4.b. Stability of equilibrium point $E_{1}$}

The characteristic matrix is state is

$$
A=\left[\begin{array}{cc}
a_{1}+a_{12} K_{2}+1 & 0 \\
0 & 1-a_{2}
\end{array}\right]
$$


The eigen values of which are $a_{1}+a_{12} K_{2}+1,1-a_{2}$. Since, absolute value of one of the two eigen values is greater than one.

Hence, $\mathrm{E}_{1}\left(0, \mathrm{~K}_{2}\right)$ is unstable.

\section{4.c. Stability of equilibrium point $\mathrm{E}_{2}$}

The characteristic matrix in this state is

$A=\left[\begin{array}{cc}1-a_{1} & a_{12} K_{1} \\ 0 & a_{2}+1\end{array}\right]$

The eigen values are $1-a_{1}, a_{2}+1$

Since, absolute value of one of the two eigen values is greater than one.

Hence, $\mathrm{E}_{2}\left(\mathrm{~K}_{1}, 0\right)$ is unstable.

\section{4.d. Stability of equilibrium point $E_{3}$}

The characteristic matrix of this state is

$A=\left[\begin{array}{cc}1-\left(\mathrm{a}_{1}+\mathrm{a}_{12} \mathrm{~K}_{2}\right) & \mathrm{a}_{12}\left(\begin{array}{c}\left.\mathrm{K}_{1}+\frac{\mathrm{a}_{12}}{\mathrm{a}_{11}} \mathrm{~K}_{2}\right) \\ 0\end{array}\right. \\ 1-\mathrm{a}_{2}\end{array}\right]$

The eigen values are

$1-\left(a_{1}+a_{12} K_{2}\right)$ and $1-a_{2}$

Case $(i)$ : When $\left(\mathrm{a}_{1}+\mathrm{a}_{12} \mathrm{~K}_{2}\right)<2$ and $\mathrm{a}_{2}<2$

The absolute value of both the eigen values is less than one.

Hence, the equilibrium point $\mathrm{E}_{3}\left(\overline{\mathrm{N}}_{1}, \overline{\mathrm{N}}_{2}\right)$ is stable.

Case (ii): When $\mathrm{a}_{1}+\mathrm{a}_{12} \mathrm{~K}_{2}=1$ and $\mathrm{a}_{2}=1$

The absolute value of both the eigen values is less than one. Hence, $\mathrm{E}_{3}\left(\overline{\mathrm{N}}_{1}, \overline{\mathrm{N}}_{2}\right)$ is stable.

Case (iii): When $\mathrm{a}_{1}+\mathrm{a}_{12} \mathrm{~K}_{2} \geq 2$ or $\mathrm{a}_{2} \geq 2$ or both $\geq 2$

The absolute value of one of the two eigen values or both the eigen values is greater than one. In this case,

$$
\mathrm{E}_{3}\left(\overline{\mathrm{N}}_{1}, \overline{\mathrm{N}}_{2}\right) \text { is unstable. }
$$

\section{A NUMERICAL APPROACH OF THE GROWTH RATE EQUATIONS}

The numerical solution of the growth rate equations (1) and (2) computed employing the fourth order Runge-Kutta method for specific values of the various parameters that characterize the model and the initial conditions. For this MATLAB has been used, the results are illustrated in Figures 3 to 12 and the observations are presented below.

\section{Results and Observations}

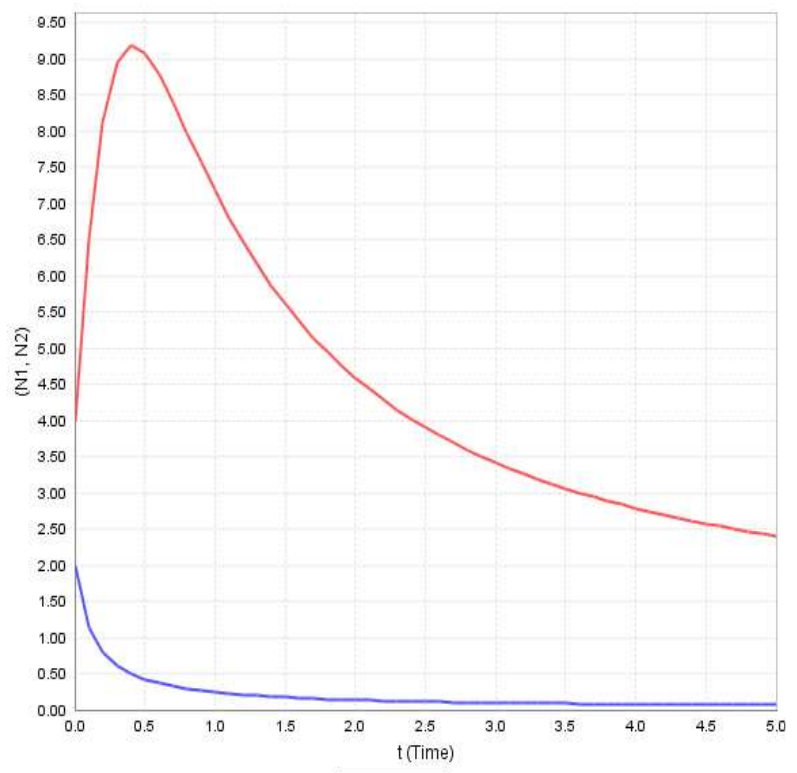

$$
-\mathrm{N} 1-\mathrm{N} 2
$$

Figure 3: Variation of $\mathrm{N}_{1}$ and $\mathrm{N}_{2}$ against time(t) for $\mathrm{a}_{1}=0.144, \mathrm{a}_{11}=0.232, \mathrm{a}_{12}=4, \mathrm{a}_{2}=0.144, \mathrm{a}_{22}=3.786$,
$\mathrm{N}_{10}=4, \mathrm{~N}_{20}=2$

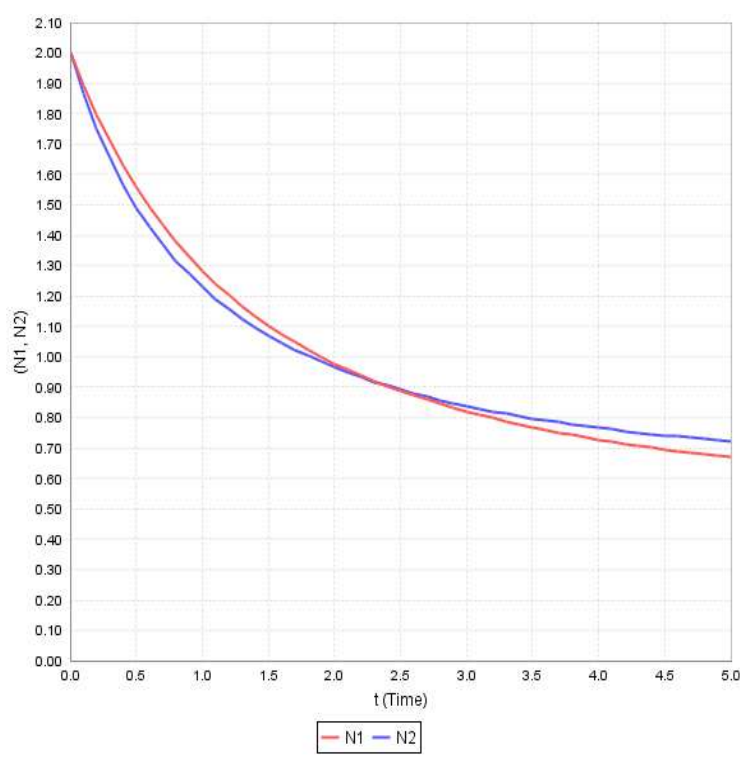

Figure 4: Variation of $\mathrm{N}_{1}$ and $\mathrm{N}_{2}$ against time(t) for

$$
\begin{gathered}
\mathrm{a}_{1}=0.125, \mathrm{a}_{11}=0.906, \mathrm{a}_{12}=0.567, \mathrm{a}_{2}=0.345, \\
\mathrm{a}_{22}=0.543, \mathrm{~N}_{10}=2, \mathrm{~N}_{20}=2
\end{gathered}
$$




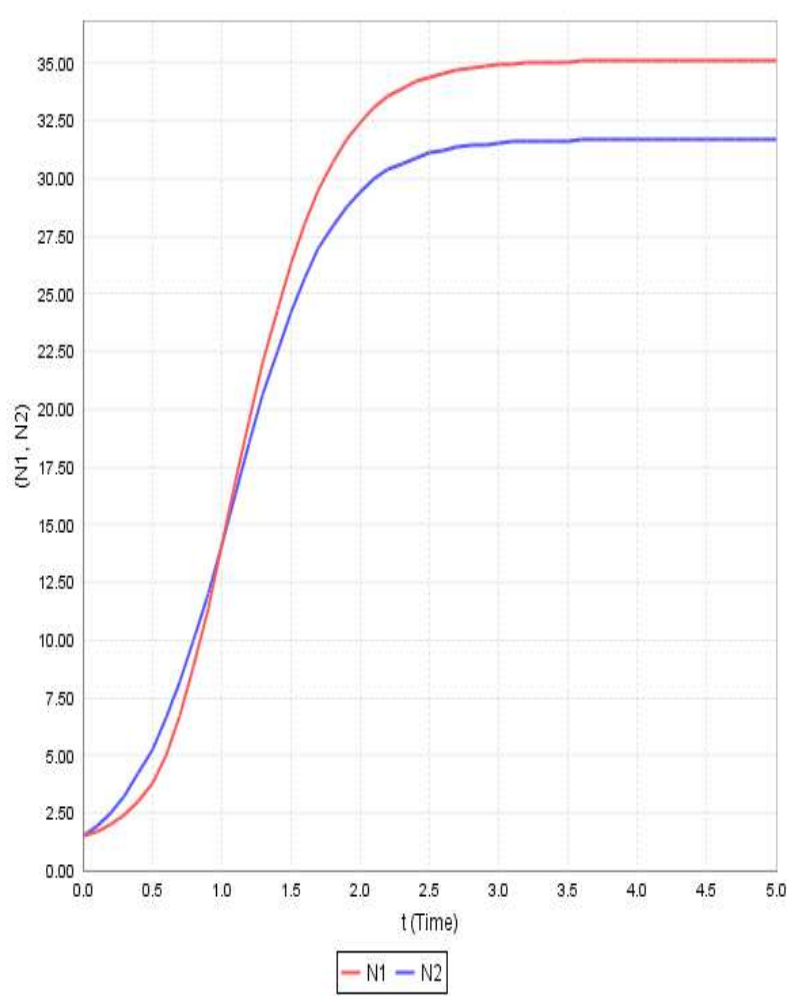

Figure 5: Variation of $N_{1}$ and $N_{2}$ against time(t) for $\mathrm{a}_{1}=1.068, \mathrm{a}_{11}=0.868, \mathrm{a}_{12}=4, \mathrm{a}_{2}=0.928, \mathrm{a}_{22}=2.788$,

$$
\mathrm{N}_{10}=1.5, \mathrm{~N}_{20}=1.5
$$

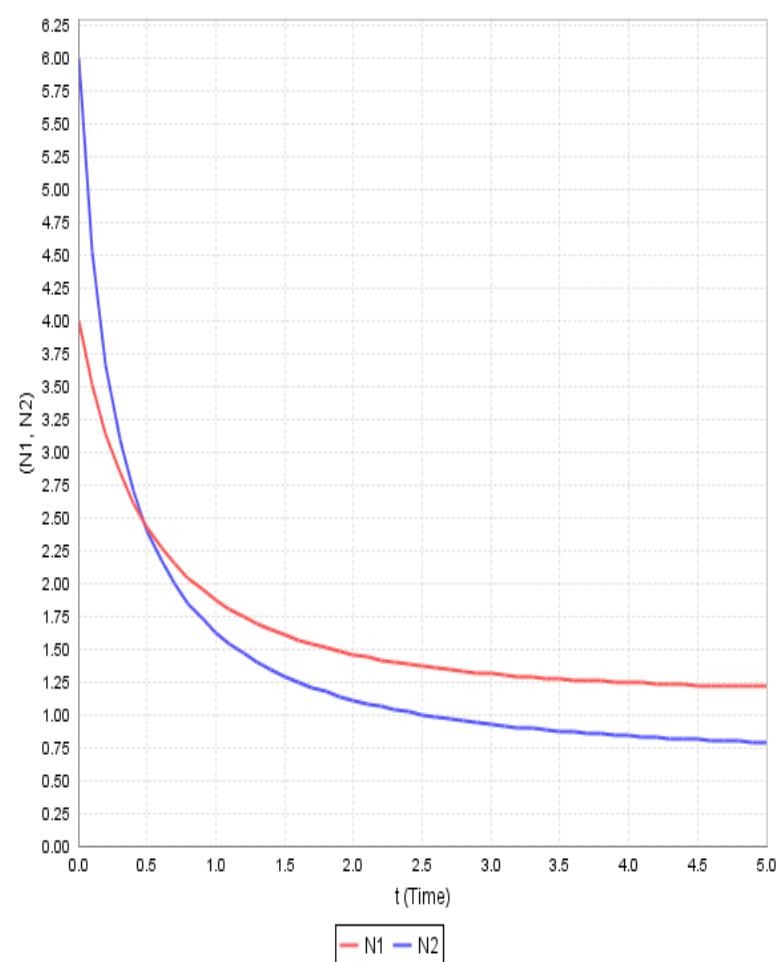

Figure 6: Variation of $\mathrm{N}_{1}$ and $\mathrm{N}_{2}$ against time(t) for $\mathrm{a}_{1}=0.753, \mathrm{a}_{11}=0.714, \mathrm{a}_{12}=0.12, \mathrm{a}_{2}=0.455, \mathrm{a}_{22}=0.633$,

$$
\mathrm{N}_{10}=4.5, \mathrm{~N}_{20}=6
$$

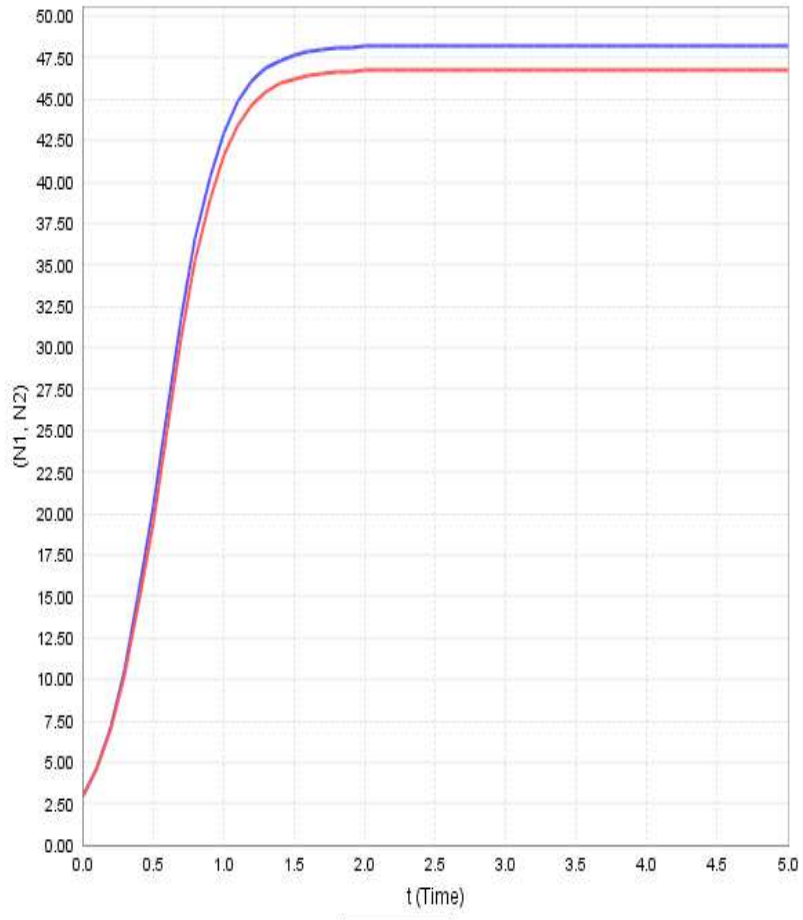

$-\mathrm{N} 1-\mathrm{N} 2$

Figure 7: Variation of $\mathrm{N}_{1}$ and $\mathrm{N}_{2}$ against time(t) for $\mathrm{a}_{1}=4.685, \mathrm{a}_{11}=0.26, \mathrm{a}_{12}=0.155, \mathrm{a}_{2}=4.82, \mathrm{a}_{22}=0.1$,

$$
\mathrm{N}_{10}=3, \mathrm{~N}_{20}=3
$$

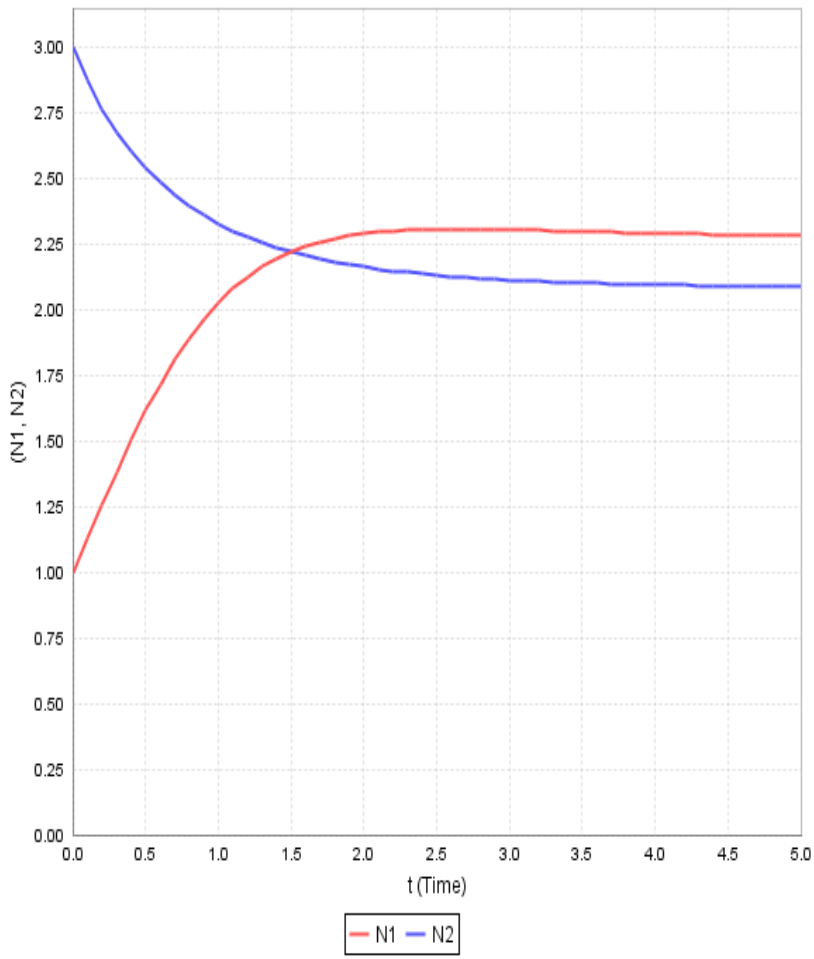

Figure 8: Variation of $\mathrm{N}_{1}$ and $\mathrm{N}_{2}$ against time(t) for $\mathrm{a}_{1}=0.405, \mathrm{a}_{11}=0.65, \mathrm{a}_{12}=0.515, \mathrm{a}_{2}=1.075, \mathrm{a}_{22}=0.515$,

$$
\mathrm{N}_{10}=1, \mathrm{~N}_{20}=3
$$




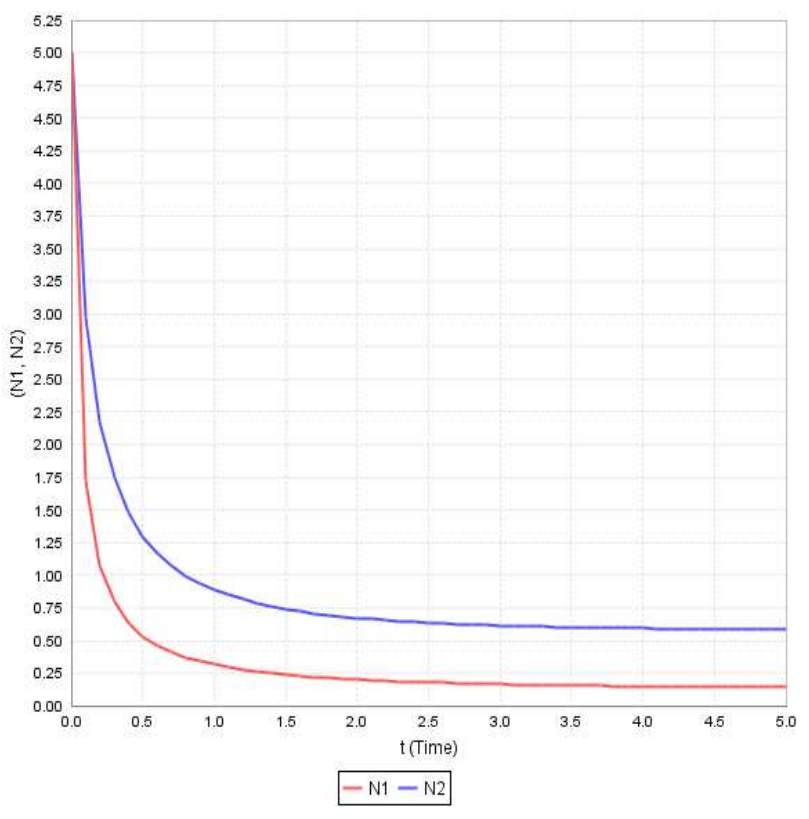

Figure 9: Variation of $\mathrm{N}_{1}$ and $\mathrm{N}_{2}$ against time(t) for $\mathrm{a}_{1}=0.405, \mathrm{a}_{11}=4.395, \mathrm{a}_{12}=0.305, \mathrm{a}_{2}=0.94, \mathrm{a}_{22}=1.615$,

$$
\mathrm{N}_{10}=5, \mathrm{~N}_{20}=5
$$

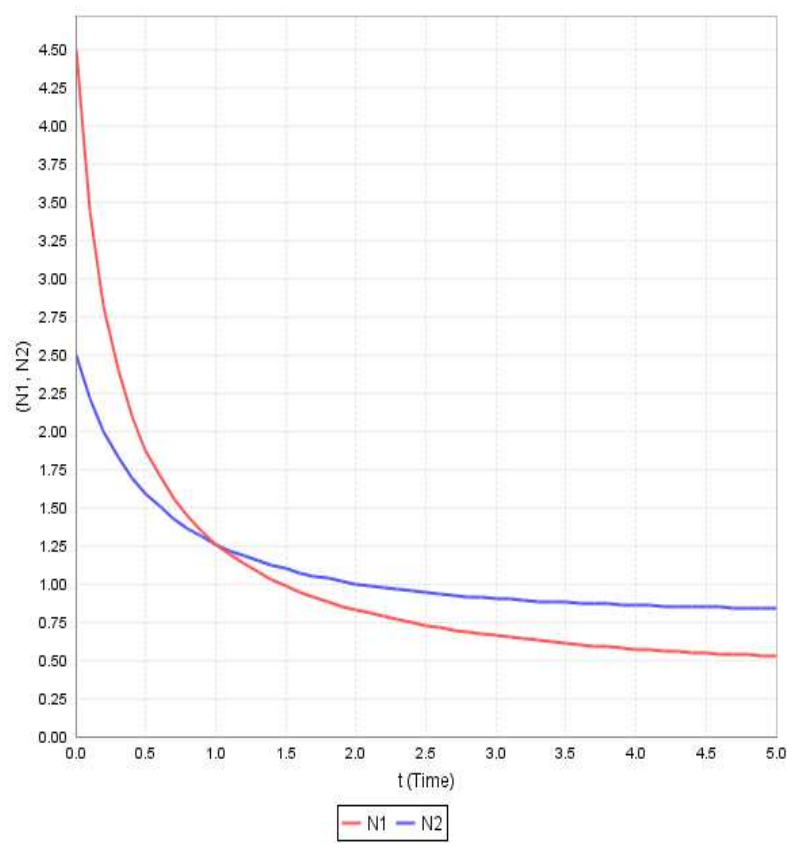

Figure 10: Variation of $\mathrm{N}_{1}$ and $\mathrm{N}_{2}$ against time(t) for $\mathrm{a}_{1}=0.144, \mathrm{a}_{11}=0.896, \mathrm{a}_{12}=0.304, \mathrm{a}_{2}=0.648, \mathrm{a}_{22}=0.792$,

$$
\mathrm{N}_{10}=4.5, \mathrm{~N}_{20}=2.5
$$

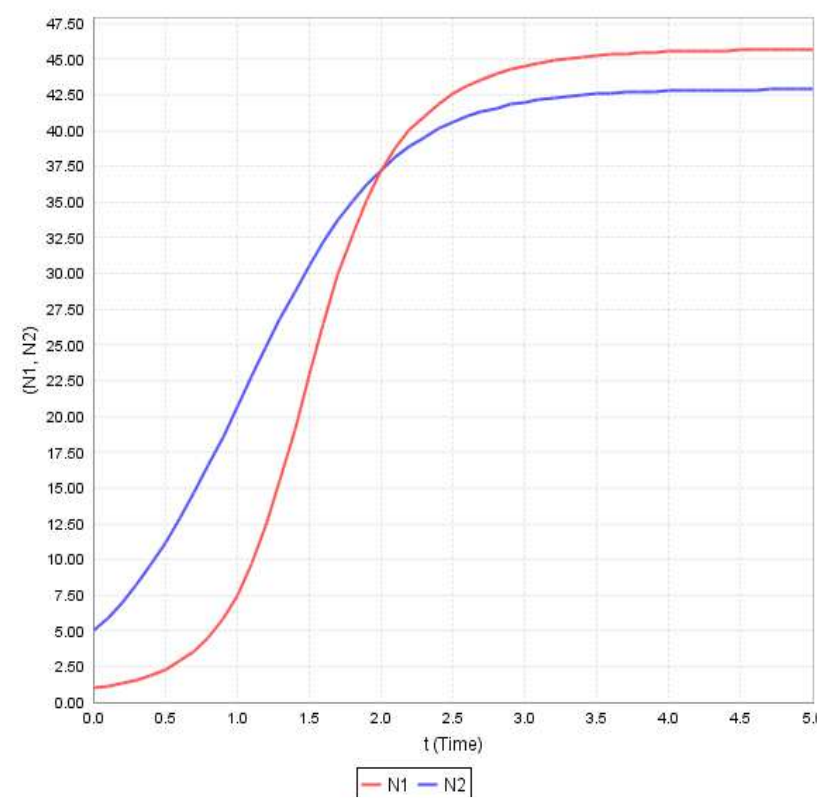

Figure 11: Variation of $\mathrm{N}_{1}$ and $\mathrm{N}_{2}$ against time(t) for $\mathrm{a}_{1}=0.91, \mathrm{a}_{11}=0.142, \mathrm{a}_{12}=0.13, \mathrm{a}_{2}=1.956, \mathrm{a}_{22}=0.046$,

$$
\mathrm{N}_{10}=1, \mathrm{~N}_{20}=5
$$

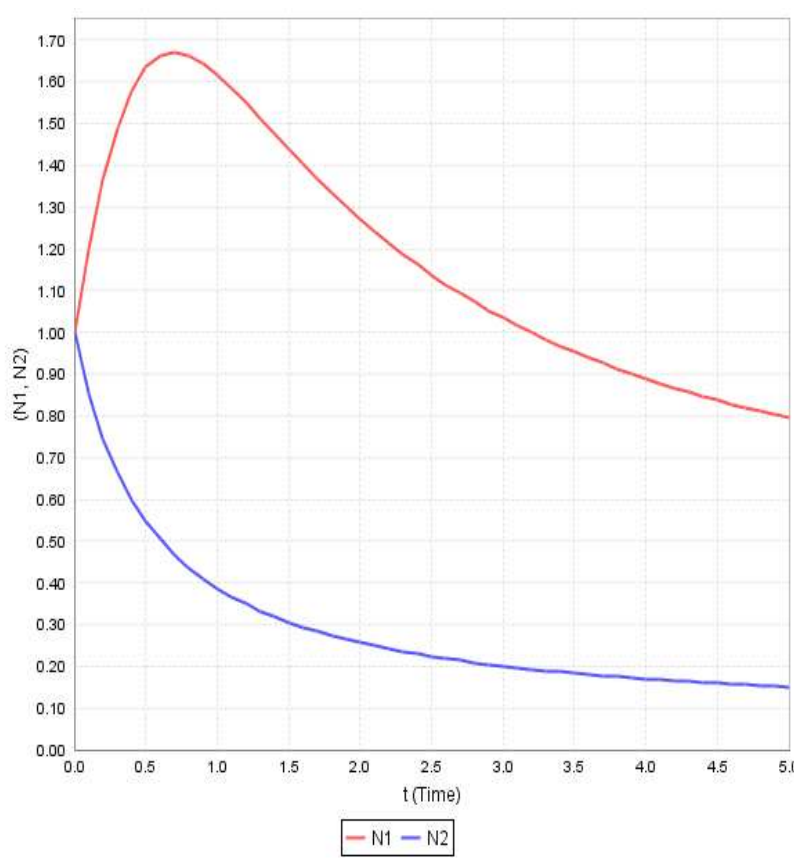

Figure 12: Variation of $\mathrm{N}_{1}$ and $\mathrm{N}_{2}$ against time(t) for $\mathrm{a}_{1}=0.21, \mathrm{a}_{11}=0.927, \mathrm{a}_{12}=2.844, \mathrm{a}_{2}=0.189, \mathrm{a}_{22}=1.923$,

$$
\mathrm{N}_{10}=1, \mathrm{~N}_{20}=1
$$




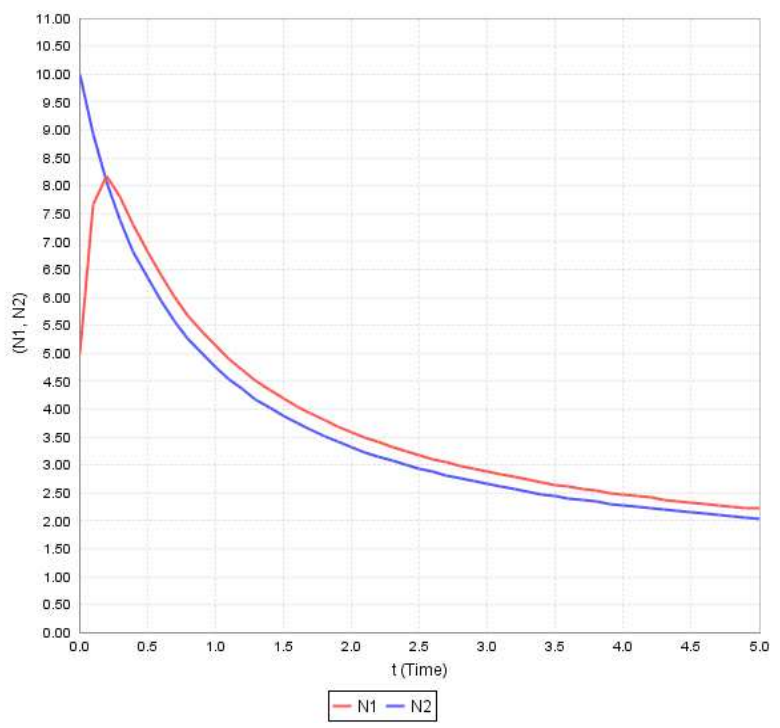

Figure 13: Variation of $\mathrm{N}_{1}$ and $\mathrm{N}_{2}$ against time(t) for

$$
\begin{gathered}
\mathrm{a}_{1}=0.230, \mathrm{a}_{11}=1.490, \mathrm{a}_{12}=1.460, \mathrm{a}_{2}=0.190, \\
\mathrm{a}_{22}=1.40, \mathrm{~N}_{10}=5, \mathrm{~N}_{20}=10
\end{gathered}
$$

\section{Observations of the above graphs}

Case-i: In this case the first species would always dominates the second species. Further the first species has a steep rise and later falls at a very low rate. The second species decreases initially and in course of time it is almost extinct as seen in Figure 3.

Case-ii: In this case initial strength of both the species is same and the first species dominates over the second species till the time instant $t^{*}=2.4$ and thereafter the dominance is reversed. Further both the species maintain steady variation with low growth rates as seen in Fig 4.

Case-iii: In this case initial strength of both the species is same and the second species dominates over the first species till the time instant $t^{*}=1$ and thereafter the dominance is reversed. Further we notice that both the species have a steady variation with no appreciable growth rates. This is illustrated in Figure 5.

Case-iv: In this case initially the second species dominates over the first species till the time instant $\mathrm{t}^{*}=0.45$ and thereafter the dominance is reversed. It is evident that both the species asymptotically converge to the equilibrium point. Further both the species maintain steady variation with low growth rates as seen in Fig 6.

Case-v: In this case initial strength of both the species is same and the second species would always dominate over the first species. Further we notice that both the species have a steady variation with no appreciable growth rates. This is shown in Figure 7.

Case-vi: In this case initially the second species dominates over the first species till the time instant $\mathrm{t}^{*}=1.5$ and thereafter the dominance is reversed. Further we see that the first species rises initially and later maintains a steady variation with no appreciable growth rate. Where as the second species decreases initially and in course of time it is almost extinct as seen in Figure 8.

Case-vii: In this case initial strength of both the species is same and the second species would always dominate over the first species. It is evident that both the species asymptotically converge to the equilibrium point. Further both the species maintain steady variation with low growth rates as seen in Figure 9.

Case-viii: In this case initially the first species dominates over the second species till the time instant $\mathrm{t}^{*}=1$ and thereafter the dominance is reversed. It is evident that both the species asymptotically converge to the equilibrium point. Further both the species maintain steady variation with low growth rates as seen in Fig 10 .

Case-ix: In this case initially the second species dominates over the first species till the time instant $t^{*}=2$ and thereafter the dominance is reversed. Further we notice that both species have a steady variation with no appreciable growth rates. This is shown in Figure 11.

Case-x: In this case initial strength of both the species is same and the first species would always dominates the second species. Further the first species has a steep rise and later falls at a very low rate. The second species decreases initially and in course of time it is almost extinct as seen in Figure 12.

Case-xi In this case initially the second species dominates over the first species till the time instant $\mathrm{t}^{*}=0.2$ and thereafter the dominance is reversed. Further the first species has a steep rise and later falls at a low rate. It is evident that both the species asymptotically converge to the equilibrium point as shown in Figure 13.

\section{CONCLUSION}

The present paper deals with the study on discrete model of commensalism between two species. The model comprises of a commensal $\left(\mathrm{S}_{1}\right)$, a host $\left(\mathrm{S}_{2}\right)$ that benefit $S_{1}$, without getting effected either positively or adversely. Al the four equilibrium points are identified based on the model equations. The model would be stable, if each of the eigen values is numerically less then one. It is observed that, in all four equilibrium states, only the coexistent state is stable when

(i) $\left(a_{1}+a_{12} K_{2}\right)<2$ and $a_{2}<2$

(ii) $\left(a_{1}+a_{12} K_{2}\right)=1$ and $a_{2}=1$ 


\section{ACKNOWLEDGMENT}

We thank to Prof..M.A.Singara Chary,Head, Dept.of Microbiology, Kakatiya University, Warangal, (A.P), India and Prof. C. Janaiah Dept. of Zoology, Kakatiya University, Warangal (A.P), India for their valuable suggestions and encouragement. And also we acknowledge to Mr.K.Ravindranath Gupta for neat typing of this research paper.

\section{REFERENCES}

[1] Lotka A. J., Elements of Physical Biology, Williams \& Wilking, Baltimore, (1925).

[2] Volterra V., Leconssen La Theorie Mathematique De La Leitte Pou Lavie, Gauthier-Villars, Paris, (1931).

[3] May,R.M. Stability and Complexity in Model Ecosystems, Princeton University Pres, Princeton, 1973.

[4] Kushing J.M., Integro-Differential Equations and Delay Models in Population Dynamics, Lecture Notes in Bio-Mathematics, Springer Verlag, 20, (1977).

[5] Smith,J.M. Models in Ecology, Cambridge University Press, Cambridge, 1974.

[6] Kapur J. N., Mathematical Modelling in Biology and Medicine, Affiliated East West, (1985).

[7] Srinivas N. C., "Some Mathematical Aspects of Modeling in Bio-medical Sciences" Ph.D Thesis, Kakatiya University, (1991).

[8] Lakshmi Narayan K. \& Pattabhiramacharyulu. N. Ch., "A Prey-Predator Model with Cover for Prey and Alternate Food for the Predator and Time Delay," International Journal of Scientific Computing. 1, (2007), 7-14.

[9]Archana Reddy R., "On the Stability of some Mathematical Models in Biosciences- Interacting Species ”, Ph.D.,Thesis, J.N.T.U, (2010).

[10]Bhaskara Rama Sharma B., "Some Mathematical Models in Competitive Eco-systems", Ph.D.,Thesis, Dravidian University,(2010).

[11]Phani Kumar, "Some Mathematical Models of Ecological Commensalism”,Ph.D.,Thesis,A.N.U. (2010).

[12]Hari Prasad.B and Pattabhi Ramacharyulu. N.Ch., "On the Stability of a Four Species : A PreyPredator-Host-Commensal-Syn Eco-System-II" (Prey and Predator washed out states) "International eJournal of Mathematics \& Engineering", 5, (2010), $60-74$

[13]Hari Prasad.B and Pattabhi Ramacharyulu. N.Ch., "On the Stability of a Four Species : A PreyPredator-Host-Commensal-Syn Eco-System-VII" (Host of the Prey Washed Out States,) "International Journal of Applied Mathematical Analysis and Applications,Vol.6,No.1-2,Jan-Dec.2011, pp.85 - 94.

[14]Hari Prasad.B and Pattabhi Ramacharyulu. N.Ch., "On the Stability of a Four Species: A Prey-PredatorHost-Commensal-Syn Eco-System-VIII" (Host of the Predator Washed Out States) "Advances in Applied Science, Research, 2011, 2(5), pp.197-206.
[15 ]Hari Prasad.B and Pattabhi Ramacharyulu. N.Ch., "On the Stability of a Four Species Syn Eco-System with Commensal Prey Predator Pair with Prey Predator Pair of Hosts-I (Fully Washed Out State)", Global Journal of Mathematical Sciences : Theory and Practical, Vol.2, No.1, Dec.2010, pp.65 - 73.

[16] Hari Prasad.B and Pattabhi Ramacharyulu. N.Ch., "On the Stability of a Four Species Syn Eco-System with Commensal Prey Predator Pair with Prey Predator Pair of Hosts-V (Predator Washed Out States)", Int. J. Open Problems Compt. Math. Vol.4, No.3, Sep.2011, pp.129 - 145.

[17] Hari Prasad.B and Pattabhi Ramacharyulu. N.Ch., "On the Stability of a Four Species Syn Eco-System with Commensal Prey Predator Pair with Prey Predator Pair of Hosts-VII (Host of $\mathrm{S}_{2}$ Washed Out States)", Journal of Communication and Computer,Vol.8,No.6,June-2011,pp.415-421

[18]Hari Prasad.B and Pattabhi Ramacharyulu. N.Ch., "On the Stability of a Four Species Syn Eco-System with Commensal Prey Predator Pair with Prey Predator Pair of Hosts-IV", Int. Journal of Applied Mathematics and Mechanics, Vol.8, Issue 2, 2012, pp. 12 - 31 .

[19]Hari Prasad.B and Pattabhi Ramacharyulu. N.Ch., "On the Stability of a Four Species Syn Eco-System with Commensal Prey Predator Pair with Prey Predator Pair of Hosts-VIII", ARPN Journal of Engineering and Applied Sciences, Vol.7, Issue 2, Feb.2012, pp.235 - 242.

[20] Hari Prasad.B and Pattabhi Ramacharyulu. N.Ch., "On the Stability of a Four Species : A PreyPredator-Host-Commensal-Syn Eco-System-IV" "International eJournal of Mathematics \& Engineering”, 29, (2010), pp. 277 - 292.

B. Hari Prasad: $\mathrm{He}$ works as an Assistant Prof. Department of Mathematics, Chaitanya Degree and PG College (Autonomous), Hanamkonda. He has obtained M.Phil in Mathematics. He has presented papers in various seminars and his articles are published in popular International and National journals to his credit. He has zeal to find out new vistas in Mathematics.

N. Ch. Pattabhi Ramacharyulu: $\mathrm{He}$ is a retired Professor in Department of Mathematics \& Humanities, National Institute of Technology, Warangal. He is a stallwart in Mathematics. His yeoman services as a lecturer, professor, professor Emeritus and Deputy Director enriched the knowledge of thousands of students. He has nearly $46 \mathrm{Ph}$.Ds and plenty number of M.Phils to his credit. His research papers in areas of Applied Mathematics are more than $\mathbf{1 9 5}$ were published in various esteemed National and International Journals. $\mathrm{He}$ is a member of Various Professional Bodies. He published four books on Mathematics. He received several prestigious awards and rewards. He is the Chief Promoter of AP Society for Mathematical Sciences. 